\title{
Effects of Social Distancing in Reducing the Spread of COVID-19 Pandemic: A Perspective of Bayelsan Residents in Nigeria
}

\author{
Ebibodere K. Baulch ${ }^{1}$, Godwin P. Angaye ${ }^{2 *}$, Edmund D. Patani ${ }^{2}$ \\ ${ }^{1}$ Department of Haematology and Immunology, Niger Delta University, Wilberforce Island, Bayelsa State, Nigeria \\ ${ }^{2}$ Department of Biology, Bayelsa Medical University, Yenagoa, Bayelsa State
}

Received: 06/09/2020

Accepted: 13/11/2020

Published: 20/03/2021

\begin{abstract}
This research work essentially explored the efficacy of social distancing in reducing the spread of corona virus disease (COVID-19) in Yenagoa metropolis. The objectives of this study were to examine the level of coronavirus disease and investigate whether social distancing have help reduce the spread of COVID-19 in Bayelsa State, Nigeria. The research design used for this study is survey, the population targeted for this study consists of residents of Yenagoa. Four hundred (400) residents were used as sample size and cluster sampling technique was applied. Instrument used for this study is the questionnaire. Results showed that the level of coronavirus disease in Yenagoa metropolis was below average, and around $70 \%$ of respondents strongly agreed that social distancing can help reduce the spread of COVID-19. Following these findings, it is recommended that social distancing and other aseptic measures should be ensured. The study concludes that social distancing can help reduce the spread of COVID-19.
\end{abstract}

Keywords: COVID-19, Social distancing, Coronavirus, Pandemic, Bayelsa State, Nigeria

\section{Introduction}

The first discovery of coronavirus, was the avian infectious bronchitis virus in 1973, which was isolated by a virologist called Fred Beaudette in 1937 [1]. This was followed in 2002 by the severe acute respiratory syndrome coronavirus (SARSCoV), and Middle East respiratory syndrome coronavirus (MERS-CoV) in the year 2012. In the year 2019 a new strain of the SAR Coronavirus (COVIS-19) was discovered in Wuhan, China. The global mobidity and mortality burden of the disease have been so overwhelming with over 400,000 cases and 20000 mortalities from 194 countries [1, 2]. As documented in literature, Coronaviruses $(\mathrm{CoVs})$ are positive-sensed single-stranded RNA viruses belonging to the order Nidovirales, family Coronaviridae, subfamily Orthocoronavirinae and four genera known as: alpha, beta, delta, and gamma coronaviruses.

Furthermore, Alpha CoVs and beta CoVs originated from bats and rodents while delta CoVs and gamma CoVs have their origins from avian species [3]. The biggest threat of the COVID-19 disease is the infectious nature, rapid spread and grave health risk it poses, especially to persons of extreme ages and underlining medical condition. COVID-19 virus primarily spreads from person to person through direct contact with an infected person [2]. Viral droplets are airborne and can be released from the mouth or nose when an infected person when he coughs or sneezes [4-6]. The virus can also spread when a person touches a surface or object that has the virus on it and then touches their mouth nose or mouth [7]. Recent studies have shown that virus may remain in surfaces or objects for up to 72 hours [2].
Social distancing has been adopted as one of the key strategies and Government policy in reducing the spread of COVID-19. The policy involves limiting person to person contact, avoidance of hand shake, public gathering, maintaining distancing not less than 1.5 meters and even restriction of movement like lockdown, quarantining or curfew as the case may be [8]. Although, these public health restrictions have had a significant adverse socio-economic impact on the populace $[9,10]$. The efficacies of this social restrictions are usually not adhered to or criticized in some quota. Notwithstanding, the global impact of the pandemic have been worrisome amidst some non-compliant critics. Therefore, it has become necessary to sample the opinion of the populace on the efficacies of social distancing in reducing the spread of covid-19.

\section{Materials and Method \\ 2.1 Research Design}

The study adopt survey as the research tool to provide information on which decisions were made. The data were sourced when by determining the answers to predetermined from the respondents. This method offers opportunity for the collation of facts from a wide range of respondents without much expense. The use of survey is a favourable because it is accurate, unstructured and can also capture time change.

\subsection{Sampling Size and Techniques}

The population included randomly selected residents of Yenagoa metropolis in Bayelsa State, Nigeria. The sample size consists of 400 residents from the study population. The sample

*Corresponding author: Godwin P. Angaye, Department of Biology, Bayelsa Medical University, Yenagoa, Bayelsa State. E-mail: maktarry@yahoo.com 
form a good representation of the population. This sample size was used in order to generate a valid data from the population. The cluster sampling technique was applied in splitting the population into groups each of which may still contain heterogeneous elements. Through random probability sampling, a sample is then picked from each cluster in accordance with the sampling plan, a simple random sampling is used.

\subsection{Instrument for Data Collection}

The instrument used for this study is the questionnaire. The questionnaire consists of open and close ended questions to guide the respondents in answering the questions it is relatively easy to analyse. The format is familiar to most respondents to think about their answers as they are not usually required to reply immediately.

\subsection{Method of Data Collection}

Data collected for this study were collected primarily with a self-administered questionnaire to the respondents, which was retrieved from them after sampling. The instrument was administered to 400 randomly selected residents in the study area, so as to prevent the problem of bias.

\subsection{Validity/Reliability of Instrument}

To ascertain the validity of the instrument, content validity was adopted. The Content validity in most cases is measured by relying on the knowledge of people who are conversant with the concept being measured. A pilot was carried out to evaluate the internal consistency of the instrument and this study took place at selected areas which is outside the study area. A total of thirty (30) respondents made up of male and female outside the sample size ( $7.5 \%$ of the total sample size) were involved in responding to the instrument due to their accessibility to Bayelsa state.

\subsection{Method of Data Analysis}

The results of the data collected were collated and statistically analysed using simple percentage to find out the extent of variation. Results were presented in tables and charts to summarise the revealed facts, and to present them in such a way that all the imported factors as contained.

\section{Result and Discussion}

A total of 400 copies of questionnaire were administered in the area under study and 388 copies were retrieved from the respondents. This represents $97 \%$ return rate. The demographic characteristics of the Respondents is presented in Figure 4.1.

The response to Table 1 shows that 161 respondents representing $41.24 \%$ were male, while 227 respondents representing $58.76 \%$ were female (Figure 1). This shows that the female responded more to the questionnaire than the male. Result presented in Table 4.1 below reveals that 191 respondents representing $49.22 \%$ were within the age brackets of $20-29$, another 111 respondents representing $38.54 \%$ fell between the age bracket of $30-39,49$ respondents representing $17.01 \%$ fell with the age brackets of $40-49$ and 29 respondents representing $7.47 \%$ had age bracket above 50 years (Table 1 ). The result presented in Table 2 below for marital status of the respondents showed that 245 respondents representing $63.14 \%$ were single, 103 respondents representing $26.55 \%$ were married, 11 respondents representing $2.84 \%$ was a divorcee, while 7 respondents representing $2.43 \%$ were reported to be either a widows or widowers. This result indicates that the single respondents were above $50 \%$, while least $(<1.00 \%)$ amongst the respondents were divorcee and widow/widower.

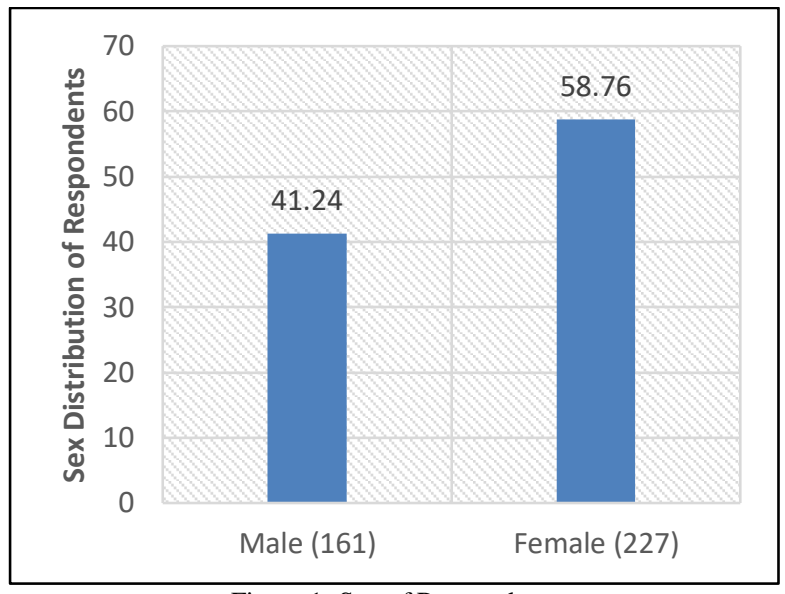

Figure 1: Sex of Respondents

Table 1: Age distribution of Respondents

\begin{tabular}{lcc}
\hline Age Brackets & No. of respondent & Percentage (\%) \\
\hline $20-29$ & 199 & 49.22 \\
$30-29$ & 111 & 38.54 \\
$40-49$ & 49 & 17.01 \\
Above 50 & 29 & 7.47 \\
Total & 388 & 100.00 \\
\hline
\end{tabular}

Table 2: Marital Status of Respondents

\begin{tabular}{lcc}
\hline Marital Status & No. of respondent & Percentage (\%) \\
\hline Single & 245 & 63.14 \\
Married & 103 & 26.55 \\
Divorcee & 11 & 2.84 \\
Widow/Widower & 7 & 2.43 \\
Total & 388 & 100.0 \\
\hline
\end{tabular}

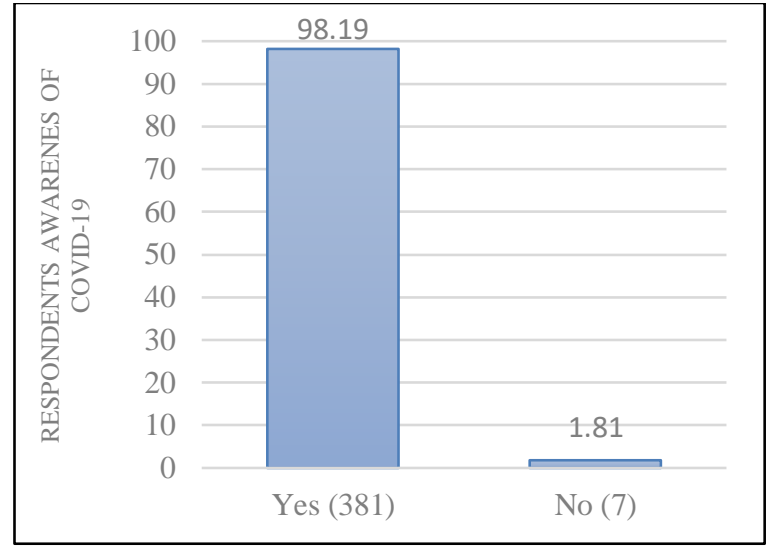

Figure 2: Respondents views on awareness of COVID-19

The awareness level of coronavirus disease in Yenagoa was investigated (Figure 2). Result shows that 381 respondents representing $98.19 \%$ of the agreed that they have heard of coronavirus disease, while the disease is still unknown to 7 respondents representing $1.81 \%$. This is an indication most of the populace are aware of the COVID-19. The source of information on COVID-19 was investigated (Figure 3), and the response rate showed that 143 respondents representing 
$36.86 \%$ said that they heard of COVID-19 through television, 119 respondents representing $30.67 \%$ said that they heard of COVID-19 from the radio, 118 respondents representing $30.41 \%$ said that they heard of COVID-19 through the social media, while 8 respondents representing $2.06 \%$ said that they heard of COVID-19 through other means (Figure 3).

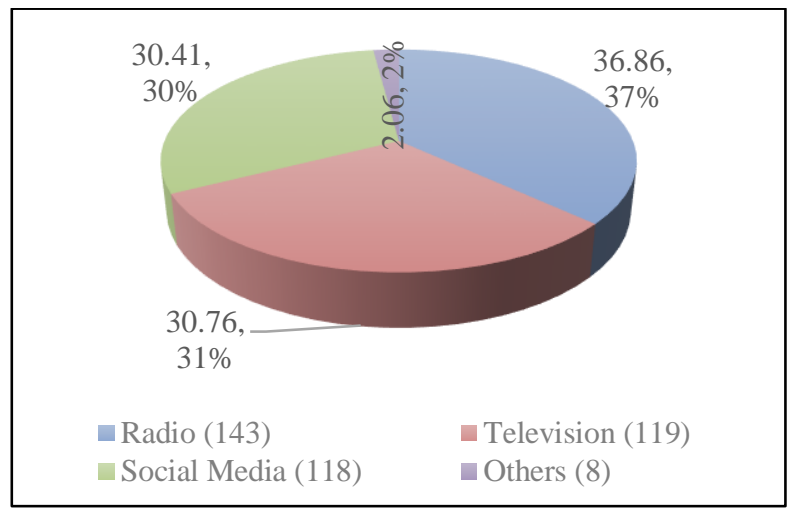

Figure 3: Respondents source of Information

Table 3: Respondents views on COVID-19 rate in Bayelsa

\begin{tabular}{lll}
\hline Ratings & No. of respondent & Percentage \\
\hline Serious & 150 & $38.66 \%$ \\
Normal & 146 & $37.63 \%$ \\
Average & 73 & $18.81 \%$ \\
Mild & 19 & $4.90 \%$ \\
Total & 388 & $100.00 \%$ \\
\hline
\end{tabular}

As presented in Table 3, the response shows that 150 respondents representing $38.66 \%$ opined that the level of coronavirus disease in Bayelsa as compared to other states of the Nigeria is serious, 146 respondents representing 37.63\% said that the level of coronavirus disease in Bayelsa is comparable to other states is normal, 73 respondents representing $18.81 \%$ of the respondents said that the level of coronavirus disease in Bayelsa was average compared to other states, while 19 respondents representing $4.90 \%$ of the respondents said that the level of coronavirus disease in Bayelsa was mild compared to other states. This means that the level of coronavirus disease in Bayelsa is comparable to other states in Nigeria (Table 3).

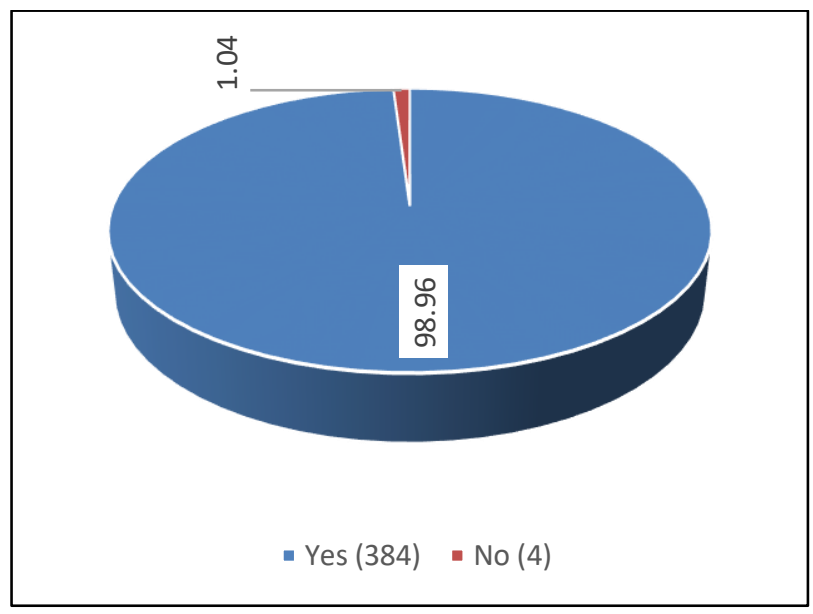

Figure 4: Respondent view on whether they have heard of social distancing as a means of reducing COVID-19
Respondent views on how social distancing will help reduce the spread of COVID-19 in Nigeria is presented in Figure 4 . The response shows that out of 388 respondents, 384 of them representing $98.96 \%$ agreed that they have heard of Social distancing as a means of reducing the spread of the COVID-19 pandemic, while only 4 respondents representing $1.04 \%$ opined that social distancing cannot reduce the COVID19 pandemic (Figure 4). Based on the outcome of the result the mantra of social distancing in reducing the spread of COVID19 have become a mainstay.

The result on if social distancing can help reduce the spread of COVID-19 shows that 274 respondents representing $70.62 \%$ of the agreed that Social distancing can help reduce the spread of COVID-19 in Yenagoa, 89 respondents representing $22.94 \%$ of the respondent agreed that social distancing and Social distancing can help reduce the spread of COVID-19 in Nigeria, 16 respondents representing $5.56 \%$ of the respondent disagreed that social distancing and Social distancing can help reduce the spread of COVID-19 in Nigeria, while 9 respondents representing $2.32 \%$ strongly disagreed that social distancing and Social distancing can help reduce the spread of COVID-19 in Yenagoa. This result implies that social distancing can help reduce the spread of COVID-19 in Nigeria.

Prior to this study, two research questions were developed to direct the course of this study. Also, the questions in the questionnaire were designed in a way that it tallies with the research question and at this point, the research questions of the study have been tested in relation to the responses of the respondents to the relevant questions on the questionnaire. The respondents $150(38.66 \%)$ agreed that the level of coronavirus disease in Yenagoa serious, $146(37.63 \%)$ respondents opined that the level of coronavirus disease in Nigeria was normal, 73 $(18.81 \%)$ of the respondents said that the level of coronavirus disease in Yenagoa was average, and $19(4.90 \%)$ of the respondents said that the level of coronavirus disease in Nigeria was mild.

This means that the level of coronavirus disease in Bayelsa is comparable to other states. This is consistent with the findings of Ugochukwu et al. (2015) which revealed that the epidemic resulted in increased knowledge of the disease as well as some misconceptions, increase in household and community hygiene practice and change in social interaction between affected individuals and the community. Prompt response by the government, with the support of international partners and proactive engagement of public health measures resulted in the rapid control of the epidemic; an experience the country hopes to leverage upon in subsequent epidemics. This goes in line with the infectious disease transmission mechanism theory which assumes that infectious disease dynamics consist of transmission as the main dynamic disease process at each hierarchical level. The second research question was answered in Table 4. Table 4 showed that $274(70.62 \%)$ respondents strongly agreed that social distancing can help reduce the spread of COVID-19 in Yenagoa, 89 (22.94\%) of the respondents agreed that social distancing can help reduce the spread of COVID-19, $16(4.12 \%)$ of the respondent disagreed that social distancing can help reduce the spread of COVID-19, while another $9(3.13 \%)$ of the respondents strongly disagreed that social distancing can help reduce the spread of COVID-19. This implies that social distancing can help reduce the spread of COVID-19 in Nigeria. This is consistent with the findings of Ugochukwu et al. [10] which revealed that the epidemic resulted in increased knowledge of the disease as well as some misconceptions, increase in household and community hygiene practice and change in social interaction between affected individuals and the community. 
Prompt response by the government, with the support of international partners and proactive engagement of public health measures resulted in the rapid control of the epidemic; an experience the country hopes to leverage upon in subsequent epidemics. This is in line with the infectious disease transmission mechanism theory. These models have been used to aid understanding of infectious disease transmission dynamics and increase our capabilities for control of infectious diseases with fewer resources.

\section{Conclusions}

This study has underscored the efficacy of social distancing in reducing the spread of COVID-19 disease in Bayelsa State, Nigeria. Findings from this research uncovered that the infectious epidemic has great socioeconomic effect on the populace, and although that social distancing was found to have efficacy in reducing the spread of the disease. Beyond the public health impact, the pandemic has socioeconomic consequences that needs prompt palliative measures. Prompt response by the government, and health care providers needs to be proactive to ensure rapid control of the epidemic.

\section{Aknowledgment}

The authors wish to than Dr. Tariwari Angaye for the experimental design and editorial inputs to review this article.

\section{Ethical issue}

Authors are aware of, and comply with, best practice in publication ethics specifically with regard to authorship (avoidance of guest authorship), dual submission, manipulation of figures, competing interests and compliance with policies on research ethics. Authors adhere to publication requirements that submitted work is original and has not been published elsewhere in any language.

\section{Competing interests}

The authors declare that there is no conflict of interest that would prejudice the impartiality of this scientific work.

\section{Authors' contribution}

All authors of this study have a complete contribution for data collection, data analyses and manuscript writing.

\section{References:}

1 Anjorin, A. A. (2020). The coronavirus disease 2019 (COVID-19) pandemic: A review and an update on cases in Africa. Asian Pac J Trop Med., 13, 10.

2 World Health Organization-WHO (2020). "Pandemic influenza prevention and mitigation in low resource communities" (PDF). World Health Organization. 2009-05-02. Retrieved 2020-03-29.

3 Cascella M, Rajnik M, and Cuomo A. (2020). Features, evaluation and treatment coronavirus (COVID-19). Treasure Island (FL): StatPearls Publishing.

4 Centers for Disease Control-CDC (2020a) "Show Me the Science - How to Wash Your Hands". www.cdc.gov. 4 March 2020. Retrieved 6 March 2020.

5 Centers for Disease Control-CDC (2020b). "Interim Pre-Pandemic Planning Guidance: Community Strategy for Pandemic Influenza Mitigation in the United States-Early, Targeted, Layered Use of Nonpharmaceutical Interventions" (PDF). Centers for Disease Control and Prevention. February 2007. CS10848. Archived (PDF) from the original on 2020-03-19. Retrieved 2020-03-29.

6 Centers for Disease Control-CDC (2020c). "Risk Assessment and Management". Centers for Disease Control and Prevention. 202003-22. Retrieved 2020-03-29.
7 Johnson, C. Y.; Sun, L.; Freedman, A. (2020). "Social distancing could buy U.S. valuable time against coronavirus: It's a make-orbreak moment with coronavirus to test one of the most basic-but disruptive-public health tools". The Washington Post. Archived from the original on 2020-03-27. Retrieved 2020-03-11.

8 Hensley, L. (2020). "Social distancing is out, physical distancing is in-here's how to do it". Global News. Corus Entertainment Inc. Archived from the original on 2020-03-27. Retrieved 2020-03-29.

9 Centers for Disease Control-CDC (2016) "Infection Control Frequently Asked Questions - Hand Hygiene". Centers for Disease Control and Prevention. Retrieved 30 September 2016.

10 Ugochukwu, U. O., Uchechi, C. E., Chuku, A., \& Huldah, I. N (2015). Ebola epidemic - the Nigerian experience. The Pan African Medical Journal. 2015;22 (Supp 1), 17 